\title{
EL OTRO JUAN RANA
}

El 20 de abril de 1672, la muerte sorprendía a Cosme Pérez en su domicilio de la calle de Cantarranas (hoy Lope de Vega), en el madrileño barrio conocido popularmente como de Las Musas, poniendo punto final a una prolífica y exitosa carrera, desarrollada por el actor más famoso del barroco español. Sin embargo, en un gesto de rebeldía que podríamos calificar de unamuniano, el personaje que creó, y que lo encumbró a la cima de la fama y el reconocimiento unánime, se negó a abandonar las bambalinas por donde había campeado a sus anchas a lo largo de más de cuatro décadas.

Es un hecho lógico y comprensible que un papel o personaje sobrevivan al actor que les dio vida en su día, y que otros intérpretes tengan la posibilidad de meterse en su piel en el futuro; sin embargo, en el caso que nos ocupa, donde la fusión del actor y el personaje fue total desde el nacimiento de este último ${ }^{1}$, no lo es tanto. Era virtualmente imposible que el público pudiera imaginar a uno separado del otro. "Mantener con vida" a Juan Rana debió concebirse como una posibilidad muy apetecible, desde el punto de vista crematístico, pero hacer olvidar a Cosme Pérez y que el público aceptara al nuevo (o a los nuevos) Juan Rana no era una empresa fácil ni cómoda para aquellos que estuvieran dispuestos a aventurarse en ella.

En el pequeño grupo de obras posteriores a la muerte de Pérez, que se conservan, se pueden comprobar las artimañas iniciales puestas en práctica para intentar convencer al público

${ }^{1}$ No hay que olvidar que a Pérez se le comienza a citar indistintamente con su nombre de pila y con el de su personaje en documentos legales desde mediados de la década de los años treinta. 
de que la vida del personaje después de la muerte del actor era posible. En algún momento, la resignación ante la imposibilidad venció al interés y la ilusión. A partir de entonces, el Juan Rana que encontramos no es más que una sombra de sí mismo, una especie de lejano recuerdo, de icono de un colectivo (el de los actores del Siglo de Oro), de símbolo de un mundo y un tiempo concretos (los del teatro áureo español), para unos espectadores que ya habian perdido el referente preciso de la dimensión del personaje que tenían delante, y el de aquél que un día le proporcionó vida escénica.

El primer hito en esta lista de obras es el entremés de $E l$ sacristán Berenjeno, escrito por Gil López de Armesto y Castro, publicado en 1674, dos años después de que Cosme Pérez apareciera por última vez metido en la piel del personaje. En esta pieza, López de Armesto decide servirse de Juan Rana de manera indirecta y hace aparecer a los dos personajes protagónicos del entremés, el sacristán y Gilote, vestidos como él², probablemente porque no se atrevió a asumir la responsabilidad de resucitar al personaje como tal. Dos son los rasgos caracterizadores de Rana que se ponen en juego al buscar la aquiescencia del auditorio: su simpleza y su manera de ejecutar el baile del zarambeque ${ }^{3}$.

La intención de mantener vivo a Juan Rana bajo otras características físicas no debió tener mucho éxito, pues prácticamente ochenta años después del Berenjeno nos topamos con el segundo ajemplo de este recorrido. Se trata del baile de La muerte de

${ }^{2}$ Véase Ramillete de entremeses de diferentes autores, Pamplona, 1700, p. 41.

${ }^{3}$ Con respecto a la primera de estas características, a Gilote se le señala con un grado tan alto de estulticia que a su lado, dirá Juana, "un Cicerón moderno fue Juan Rana" (Ramillete de entremeses..., p. 40). Asimismo, el personaje se autodefinirá como "el tonto mayor" al final de la pieza (ibid., p. 46). En cuanto a la escena del zarambeque, el sacristán y Gilote se ven obligados a bailarlo como en una especie de duelo que servirá para dirimir quién de los dos es el verdadero Rana: "Gilote - ...Vava otra habilidad. (Aparte.) Aquí le gano. / A un zarambeque os reto. SACRISTAN - (Aparte.) Mala mano. JUANA - (Ap.) iAy, Berenjeno! En este lance infiero / te ha de ganar porque es tamborilero. SACRISTAN - (A $p$.) Calla, que las mudanzas celebradas, / es el dar a compás vuelta y patada... JUANA - (Ap.) El alma está en un tris. GILOTE - $(A p$.) De ésta le gano al seor chisgarabís. / Toque vuesamerced, seor mosiquero, / aunque mijor bailara yo a un pandero. / (Baila Gilote el zarambeque.) Gilote - ¿Qué os parece tío? Vejete - Lindamente... Juana - (Ap.) Mi amor vaya contigo. SACRISTÁN - Con tu favor, no temo a mi enemigo. / (Baila el Sacristán el mismo zarambeque.) SACRISTÁN - ¿Qué os parece? VFJETE - Famoso y admirable, / y que el juicio está indeterminable" (ibid., pp. 44-45). 
Juan Rana, cuya única copia conocida se encuentra en un tomo de manuscritos que con el título de Libro de bailes de la señora María Hidalgo está fechado en 1750. Sabedor, tal vez, y consciente del nulo éxito que habían tenido aquellos que intentaron la resurrección o reanimación del personaje (seguramente, en más ocasiones de las que hoy en día tenemos noticia), el anónimo autor del baile ofrece una ingeniosa propuesta: partiendo de una premisa completamente verosímil, ya que acepta la "muerte" de Juan Rana (en realidad, la de Cosme Pérez, que para el caso era lo mismo), presenta una solución intermedia que todos (público, personaje y otros hipotéticos futuros autores) podrían aceptar: Rana ha muerto, sí, pero le ha sobrevivido Juan Ranilla, un hijo tan idéntico a él que garantiza, sin ningún tipo de conflicto para el público, el disfrute de las gracias de "su padre". El autor de esta pieza decidió apostar por la continuidad de todas las características de aquél en un personaje que oficialmente es otro, pero que de cara al espectador podría tener idéntica validez que el original ${ }^{4}$.

El personaje es hábil en el cante (posiblemente como recuerdo del buen número de escenas cantadas que, haciendo las delicias del público, interpretó Rana con la peculiar voz que debió tener Pérez) y el baile (sin que en esta ocasión se especifique su maestría con el zarambeque). De la chispa cómica que caracterizó a su progenitor o del tan socorrido recurso a la simpleza del personaje, no encontramos rastro ${ }^{5}$.

${ }^{4}$ Para un estudio más detallado sobre esta obra y su edición crítica, remito a mi artículo "La muerte de Juan Rana, como constatación de su pervivencia", CuLH, 2004, núm. 29 (en prensa).

${ }^{5}$ Sin embargo, es curioso constatar cómo, por esos mismos años, para el padre FejJoo, Juan Rana, como nombre propio, era sinónimo de la quintaesencia de lo gracioso teatral. Así lo deja patente en el discurso décimo ("Amor de la Patria, y pasión nacional") del t. 3 (1729) de su Teatro crítico universal. En el tercer apartado de este texto, que trata sobre el sentimiento chovinista connatural a todos los pueblos, Feijoo describe de esta manera el modo en el que los nacidos en una patria o región determinada se sienten mejores y/o superiores a sus vecinos: "Sólo en su nación hay hombres sabios, los demás son punto menos que bestias. Sólo sus costumbres son racionales. Sólo su lengua es dulce y tratable. Oír hablar a un extranjero les mueve tan eficazmente la risa, como ver en el teatro a Juan Rana. Sólo su región abunda de riquezas. Sólo su príncipe es poderoso". Una última referencia a nuestro actor se puede encontrar en el discurso décimo ("Verdadera y falsa urbanidad") del t. 7 de la misma obra (1736). Aunque se le trae a colación con el mismo propósito que en la referencia anterior (como el paradigma del personaje o actor cómico por antonomasia), en esta ocasión 
Otro siglo más tarde, en el también anónimo pasillo cómico de Juan Rana y Antón Rapao, nuestro gracioso hace gala de una conducta sorprendente, viniendo de él. En primer lugar, habría que destacar la actitud chulesca con la que se impone a un Antón Rapao que por su marcada cobardía y deseo de saciar sus necesidades más primarias (hambre y sed, que manifiesta al comienzo de la pieza), recuerda más al Juan Rana de antaño que al Rana actual. En la escena inicial, cuando ambos se encuentran en un callejón oscuro, nos topamos con este pasaje:

$\begin{array}{ll}\text { JuAN RANA } & \text { ¡Hola! ¿Quién va? } \\ \text { ANTÓN RAPAO } & \text { ¡Hola! ¿Quién viene? } \\ \text { JuAN RANA } & \begin{array}{l}\text { Un tigre, león, serpiente, } \\ \text { que sale aquí de repente, } \\ \text { a arrancarte el corazón. }\end{array} \\ \text { AnTÓN RAPAO } & \begin{array}{l}\text { Tiene usted mucha razón; } \\ \text { dice usted muy lindamente. }\end{array} \\ \text { JUAN RANA } & \text { ¡Saca la espada! } \\ \text { ANTÓN RAPAO } & \text { No puedo. }\end{array}$

\footnotetext{
el comentario no es tan amable, ya que si bien es cierto que Rana atesora esa característica, también lo es que ésta se sustenta en la banalidad e in trascendencia. El apartado decimocuarto de dicho discurso está dedicado a la "jocosidad desapacible" y dice así: "Pero tanto, y aún más, que se opone a la urbanidad la seriedad nimia, es contraria a ella la jocosidad inoportuna. Por tres capítulos puede ser ingrata la chanza en las conversaciones: por exceder en la cantidad, por propasarse en la calidad y por defecto de naturalidad. El que está siempre de chanza, más es truhán que cortesano. No hay hombre más irrisible que el que siempre se ríe. El que a todas horas hace el gracioso, a todas horas es desgraciado. Un juan Rana de por vida es lo que suena, un Juan Rana y nada más". Con similares connotaciones traerá a colación el nombre algunos años después RıMóN DE LA CRcz en su sainete titulado Las castañeras picadas. En un momento, el personaje de dona Javiera expresa las dificultades que supone que va a tener para encontrar un sustituto digno para su difunto esposo: "JAVIERA - ...jAy, Ceferina! / iAhora conozco las maulas / que son los hombres! (Suspirando.) iAunque / con un candil le buscara, / no hallaré otro Juan García! BLAs - Pues buscarle con un hacha, / y en encontrando un buen Juan, / más que se llame Juan Rana” (Sainetes, ed. F. Lafarga, Cátedra, Madrid, 1990, pp. 397-398).
} 
JUAN RANA ¿Quién te lo impide?

ANTÓN RAPAO El miedo.

JuAn Rana ¿De qué le tienes?

ANTÓN RApao De nada.

JuAN RANA :Váyase!, que es un cobarde.

Antón RAPAo Pues, si no fuera tan tarde, sepa usted que peleara ${ }^{6}$.

A continuación, y olvidando riñas y cuernos con que le dispensaron sus esposas escénicas en el pasado, Rana vuelve a sorprender, esta vez con un breve discurso apologético sobre el matrimonio y sus excelentes efectos. Comenzará defendiendo ante Rapao que:

Todo el hombre que es soltero, trae inquieta la paciencia y nunca tiene un dinero, y para más bien hallarse y que siga la virtud, tener caudal y salud, es buscar con quien casarse y de tropiezos quitarse. Y si no contempla tú qué gustos y qué placeres traen consigo las mujeres cuando anda el casamiento

Y finalizará, llegando a la conclusión de que

...un hombre casado tiene mujer que le asista y le ayude a sus cuidados. ¡Mira si se puede dar, estado de más regalo!

(f 3 a).

${ }^{6}$ Cito por Juan Rana y Antón Rapao. Pasillo, Madrid, 1844, f. 1 b. Los folios aparecen sin numerar. 
Una vez más será Rapao el que lleve la contra y defienda una postura diametralmente opuesta, mucho más acorde con la forma de ser y pensar a las que el Juan Rana barroco tenía acostumbrados a los espectadores.

La parte final de la obra constituye una especie de crítica antieclesiástica que aparece incorporada al resto de una manera un poco forzada. En ella, ambos protagonistas analizan las opciones que consideran más propicias para "servir a Dios", y deciden convertirse en peregrinos y recorrer el mundo. Justo antes de emprender el peregrinaje se despiden del público y se da por concluido el pasillo.

Con Los comediantes de antaño llegamos a la primera de las dos incursiones en la denominada "zarzuela grande" que protagonizó nuestro personaje. Con música del maestro Barbieri y libreto de Mariano Pina y Bohigas, la obra fue estrenada en el teatro de la Zarzuela de Madrid, el sábado 14 de febrero de $1874^{7}$. El personaje de Juan Rana, según se indica en el listado de dramatis personae, fue interpretado por el "Sr. Castilla", que, tal y como queda reflejado en el número de El Popularmencionado en nota, hizo "...las delicias del público en la interpretación del bonito papel del que se halla encargado"8.

${ }^{7}$ Este dato aparece consignado en la sección de espectáculos del periódico madrileño El Popular que, con fecha de lunes 16 de febrero, da noticia de que la zarzuela se estrenó "la noche del sábado", esto es, el día 14. Sin embargo, en la portada del libreto impreso de la zarzuela se dice que fue representada por primera vez en el teatro de la Zarzuela de Madrid el "13 de febrero de 1874".

${ }^{8}$ Son sólo tres (aparte de la obra que estamos tratando) las referencias que hemos podido encontrar de Gabriel Castilla, siempre relacionadas con obras de Barbieri. En 1870 estrenó la zarzuela grande titulada Robinsón, musicalizada por éste y escrita por Rafael García Santisteban. Se escribió para los denominados Bufos de Arderius (nombre que tomaban de Francisco Arderius, creador de este tipo de género cómico-burlesco) y se convirtió en un gran éxito representándose en toda España. Más tarde, concretamente en 1877, protagonizó el juguete cómico en un acto titulado Artistas para La Habana, escrito por Rafael María Liern y con música también de Barbieri. Por último, se conserva una nota de Liern dirigida al compositor en la que dice: "Me ocupo actualmente en escribir un juguete titulado El bolero afligido, con destino al Teatro Eslava y para que lo estrene Gabriel Castilla. El protagonista del juguete es nuestro célebre personaje de Artistas para La Habana..." (Emilo Casares Ronicio, Francisco Asenjo Barbieri, Instituto Complutense de Ciencias Musicales, Madrid, [1994], t. 1, p. 400). La obra no se concluyó, ya que pocos días después de que Barbieri contestara esa nota murió en Madrid. Por otra parte, he podido hallar brevisima noticia de la 
Sin poder cuantificar lo merecidamente elogiosas o no de estas palabras, lo cierto es que el personaje quedó convertido en esta zarzuela en una especie de elemento ambientador de la época en la que transcurre la historia. Un par de comentarios que parecen evocar su proverbial glotonería es lo poco que todavía hace recordar al gracioso que triunfó sobre los escenarios dos siglos antes ${ }^{9}$. Por lo demás, bien se podría afirmar que nos encontramos ante un personaje totalmente diferente que desde el primer momento se muestra consciente de su propia identidad ${ }^{10}$, y que se presenta como actor (en realidad, como auténtico maestro de la representación que al comienzo del Acto Segundo vemos impartiendo lecciones de declamación), autor de compañía e incluso encargado de la maquinaria y vestidos en las representaciones de

elección que de esta obra hizo la tiple Francisca Selgas Aguado para su debut en México, en abril de 1879. En la entrada que Baltasar SALDONI dedica a esta cantante en su Diccionario biográfico-bibliográfico de efemérides de músicos españoles (Imprenta de D. Antonio Pérez Dubrull, Madrid, 1868-1881, t. 4, pp. 320-321. Existe una ed. facs. preparada por Jacinto Torres, Centro de Documentación Musical-Ministerio de Cultura, Madrid, 1986), se refieren también los nombres de los actores que participaron en la representación de la obra junto a ella. Aparece el nombre de un tal Iglesias, de quien se dice que actuaba como tenor cómico, por lo que suponemos que sería el actor encargado de dar vida a Juan Rana en aquella ocasión. No he podido encontrar otra noticia sobre este actor.

${ }^{9}$ En una ocasión afirmará: "MeLCHOR - ...En cuanto a los comediantes / aquí pueden descansar (Señalando al mesón), / que ya tienen preparados / dos graneros y un desván. Cosme - ¿Y despensa? Melchor - ¡Con dos lomos / en escabeche que ya! Cosme - Pues, a esos lomos me agarro". En otro momento, esta vez en el transcurso del Acto Tercero, dirá: "Cosme - Pues, señor, aquí se trata / la gente a cuerpo de rey. / Me han dado unos polvorones / y un añejo de Jerez, / que reaniman el estómago / de un muerto" (Marlano Pina y Francisco B $\backslash$ rbieri, Los comediantes de antaño, Imp. de José Rodríguez, Madrid, 1874, pp. 27 y 82). Quisiera aprovechar estas líneas para agradecer a María Luisa Lobato la amabilidad que tuvo al darme a conocer la existencia de esta obra.

10 Parece bastante evidente que el Cosme Pérez de esta zarzuela tiene mucho interés en marcar bien las diferencias entre su identidad como persona y la del personaje que interpreta, ya que en dos ocasiones corrige a las personas que se dirigen a él utilizando el nombre Juan Rana: "MARQués ....A qué viene / el comediante Juan Rana / a este pueblo? Cosme - Cosme Pérez. Marqués - Por Juan Rana te conocen / en jácaras y entremeses. CosME - Vengo con mi compañía a trabajar". Y más adelante: "Maroués - ...No tengas miedo buen Juan. Cosme - Cosme". En esta ocasión, Cosme parece rebelarse ante la velada calificación de "tonto" o "simple" que, por medio de la acepción que tradicionalmente tiene este nombre, parece emplear el marqués (ibid., pp. 17 y 84). 
la obra ${ }^{11}$. Enamoradizo, codicioso ${ }^{12}$, con rasgos de ruindad ${ }^{13} y$ cómplice en labores de tercería en favor del personaje del marqués de Benavente, las únicas ocasiones en las que el autor parece buscar la vena cómica del personaje es por medio del recurso de la violencia física (no presenciada en escena, sino referida) muy alejada de nuestra mentalidad actual y también de aquellos "cándidos" (si se permite el uso de este adjetivo para aludir a su origen conceptual) finales a golpes tan habituales en el género breve barroco. Hemos pasado a la búsqueda de la carcajada mediante una presunta comicidad tosca, simplona y descontextualizada. Varios son los ejemplos que se pueden traer a colación. En el primero, Rana describe al marqués de Benavente su comportamiento en los dos matrimonios por los que ha pasado:

Cosme ...Siempre en mis bodas
presidió mano enemiga.
De mi difunta consorte
disfruté un mes las caricias,
pero la mano fatal
me robó tan grata dicha,
y aquel ángel falleció
de mi primera paliza.
Con mi segunda mujer,
que amo con idolatría,
me casé en el carnaval,
y el Miércoles de Ceniza,
de la propia mano a impulsos,
le rompí cuatro costillas,
con tal suerte que ha diez meses

11 Ibid., p. 76.

12 "Cosme - (Aparte.) Oigo entre palmadas / bravos resonar, / y el dinero cuento / que ellos me han de dar / Gozo ya en el triunfo / de una y otra actriz, / y con mis ganancias / voy a ser feliz". Y refiriéndose al auto cuya representación está preparando en el Acto Tercero dirá: "Cosme - ...Por hacer en buena mula / un par de horas de camino, / bebo, como y aseguro / treinta ducados en limpio" (ibid., pp. 38 y 77 ).

13 No dudará en mostrar su alegría por el provecho que podrá obtener de la fuerte discusión entre el personaje de Luisa, actriz de su compañía de la que está enamorado, y el marqués de Benavente: "Cosme - (Aparte.) Los fieros celos / en esta lid / han puesto a Luisa / fuera de sí. / Y, bien mirado, / no escapo mal / en esta lucha / de odio infernal... Lursa - (Al Marqués.) Tu risa se ha cambiado / en llanto de dolor. Maroués - (A Luisa.) ¡Mal haya una y mil veces / tu faz de maldición! Cosme - Después de esta tragedia, / quien gana aquí soy yo" (ibid., pp. 65-66). 
y está en cama todavía.

¡La mano! ¡Siempre la mano!

MARQuÉs ¡Pues, es mano divertida!

(p. 42).

El personaje aparece caracterizado como una especie de perturbado que sufre arrebatos de agresividad incontrolables de los que se muestra totalmente consciente. Más adelante, en una conversación con Luisa (actriz de la que, ya hemos comentado, está perdidamente enamorado), ésta intenta aprovecharse del influjo que sabe que tiene sobre él para pedirle que expulse de la compañía a Aurora, mujer a la que el marqués, a su vez, ama perdidamente. De este modo, Luisa podrá tener vía libre para ganar el corazón del marqués. Cuando Cosme ha prometido que hará lo que esté en su mano para cumplir su deseo, asistimos al siguiente diálogo:

LuISA (Cogiéndose de su brazo) ¡Ay, Juan! ¡Si fueras viudo!

Cosme ¡Ay! ¡Si fueras mi mujer! (Haciendo sin que ella lo vea la demostración de pegar...) (p. 52).

Más adelante, informando al marqués del plan que Luisa ha tramado, dirá sobre ella:

Cosme Si ella fuera mi mujer la corrección era fácil; (Haciendo la acción de pegar.) mas lo usual en un marido le está vedado al amante

$$
\text { (p. 60). }
$$

Por último, justo al final de la zarzuela, Luisa, despechada por la decisión del marqués de Benavente de casarse con Aurora, opta por hacer lo propio con Cosme Pérez, cumpliendo así los deseos que éste ha mostrado a lo largo de la obra. Es en este momento cuando nos enteramos de la suerte que ha corrido la segunda esposa de Rana: 
Luisa $\quad$...yo también me caso.

MARQUÉS ¿De veras?...

(Aparte a Luisa.)

$\mathrm{Y}$, ¿quién es el pobre incauto

que aspira....?

Luisa (Señalando a Cosme.)

Éste que aquí veis.

Marqués (A Cosme.)

¡Ah!... ¿Tu mano hace dichosa

a Luisa?

Cosme ¿Eh?

LUISA Cedo a sus clamores.

Cosme ¿Qué oigo? ¿Cesan tus rigores?

MARQuÉs (Aparte a Cosme.)

Pero..., ¿y tu segunda esposa?

Cosme (Ídem al Marqués.) Soy viudo, y como ésta me ama...

MARQUÉS ¿Ah! ¿Falleció tu segunda?

Cosme De resultas de la tunda

que la tuvo un año en cama.

$Y$ si en situación ridicula

esta tercera me embute...

MARQUÉS (Aparte.)Ya estoy vengado.

Cosme (Íd. al Marqués.) De un tute

le disloco una clavícula

$$
\text { (p. 90). }
$$

Por todo lo visto, se puede concluir que el Juan Rana creado por Mariano Pina y Bohigas no es más que una lejana reminiscencia del original. Por medio de lo que podríamos denominar la pérdida de la inocencia, sirve de vago recuerdo de quien fue y también de elemento caracterizador de una época (la que él vivió), para un público incapaz de trazar una línea de comparación entre la esencia del personaje que fue y el que ahora tiene delante; el público era incapaz de advertir la transformación a la que se 
le había sometido. La manera en la que el personaje aparece construido hace pensar en el verdadero nivel de conocimiento que $\mathrm{Pi}$ na y Bohigas tenía de él al decidir incluirlo en su libreto ${ }^{14}$.

De nuevo, el motivo metateatral es la excusa perfecta para insertar a Juan Rana en el reparto de Don Lucas del Cigarral, zarzuela en tres actos cuyo libreto, musicalizado por Amadeo Vives, escribieron al alimón Tomás Luceño y Carlos Fernández Shaw. La obra, refundición de la comedia de Francisco de Rojas Entre bobos anda el juego, se estrenó en el Teatro de Parish, en Madrid, el 17 de febrero de 1899. El papel de Juan Rana fue in-

\footnotetext{
14 Aunque no podemos discernir cuán familiarizado pudiera estar Pina y Bohigas con el personaje de Juan Rana, creemos que puede ayudar a formar una buena idea al respecto el dudoso conocimiento que sobre la figura de Cosme Pérez existía en la época. Como ejemplo, valga la noción que se puede extraer del siguiente fragmento de un artículo que el maestro Barbieri (autor de la música de la zarzuela y autoridad en materia teatral de su época) publicó en 1878 en La llustración Española y Americana, y donde contesta y corrige a Julio Monreal por haber ofrecido datos erróneos sobre el actor en un artículo suyo anterior. En este trabajo, "Más sobre las danzas y bailes en España en los siglos xvı y xvı", apunta: “...Esta falta se hace mucho más grave cuando se trata de asuntos biográficos, como lo hace el Sr. Monreal en su primer artículo del 22 de agosto de 1874. En él pone en escena dos personajes muy conocidos en la historia del teatro, los célebres comediantes Cosme Pérez Juan Rana, y la famosa Jusepa Vaca. Al primero le presenta como un bululú, borracho y sin vergüenza, que va de pueblo en pueblo especulando con los atractivos de una bailadora de diez y siete años de edad, que dice ser la dicha Jusepa. Tal cosa no puede admitirse en buena crítica, cuando está averiguado que Cosme Pérez fue hombre de costumbres ejemplares, propietario de unas casas en la calle de Cantarranas, y el gracioso más célebre de su tiempo, quien, después de figurar en las mejores coinpañías cómicas, murió en Madrid el año 1673" (véase Casares Rodicio, op. cit., t. 2, p. 368). Ni Cosme Pérez murió en 1673 ni la mentalidad de la época hubiera podido considerar sus costumbres como ejemplares teniendo en cuenta que su episodio biográfico más famoso, y que llegó a afectar incluso la caracterización escénica de su personaje, fue el proceso judicial que sufrió en el otoño de 1636 tras ser acusado de practicar la sodomía. Barbieri, por tanto, tampoco tenía un excesivo conocimiento de la vida de Pérez o bien decidió imaginar, siempre bajo el prisma moral de la época, aspectos biográficos que consideraba más acordes con un personaje de la talla de nuestro actor. De esta forma podía justificar su importancia en el mundo teatral de un período mítico para la historia de España, su estrechísima relación con Felipe IV y su familia, y, en especial, con su segunda esposa, la reina Mariana de Austria. Por su parte, Eusebio BLAsco dirá de nuestro personaje, de manera escueta, que era famosísimo “...en España y aun fuera de ella dos siglos ha" (Mis contemporáneos. Semblanzas varias, F. Álvarez, Madrid, 1886, p. 165).
} 
terpretado en esta ocasión por un tal "Sr. Rubio" que también daba vida en la obra al personaje de un mesonero ${ }^{15}$.

Rana interviene únicamente en un par de ocasiones durante la representación, convirtiéndose su presencia más que nunca (junto a la de otros famosos comediantes de su época como Antonio Prado, Jusepa Vaca o Manuela de Escamilla) en una especie de nota de color utilizada como elemento ambientador de la época en la que transcurre la zarzuela, en general, y de la vida teatral propia, en particular.

Sin embargo, y a pesar de la brevedad de su intervención, su participación no está exenta de relevancia argumental, sucede más bien lo contrario. Lo que se pide a él y "a su tropa" (a los que se define como "el orgullo y la prez de la comedia española") ${ }^{16}$, es que representen una farsa cuya historia es, precisamente, un remedo de la de don Lucas con todos sus vicios y defectos. El motivo central será el matrimonio concertado a la fuerza por el padre de doña Isabel (movido únicamente por el interés en el caudal que atesora aquél), aunque, como siempre suele ocurrir en estos casos, ella está locamente enamorada de un hombre más afín en edad y cualidades físicas y morales que, sin embargo, es pobre: don Pedro, primo de don Lucas. Durante la representación de la farsa, se espera que don Lucas comprenda que se están aludiendo a su persona y circunstancia, recapacite, y desista de celebrar matrimonio tan injusto, permitiendo que doña Isabel se despose con quien verdaderamente desea.

Rana interpreta en estejuego metateatral a un viejo llamado don Inocencio, trasunto de don Lucas, al que imita, según se explica en acotación, "en la cara, en el traje y en los ademanes”. Según avanza la representación de este entremés interno, don Lucas se percata de la chanza que se esconde en su doble intención, hasta que llega el momento en que no puede seguir

15 ¿Será este señor Rubio el famoso actor cómico Pepe Rubio? Aunque en sus memorias no hace mención a esta obra, es probable que así fuera. Durante la temporada 1898-1899 dice que participó en veintiséis estrenos, de los que sólo considera dignos de destacar cinco. Por su parte, en la temporada siguiente, 1899-1900, actuó en doce, de los que sólo resalta cuatro (José Rubio, Mis memorias. Treinta y nueve años de actor y catorce de profesor numerario de declamación del Real Conservatorio de Madrid, F. Beltrán, Madrid, 1927, pp. 129 y 132). Es muy posible que nuestra zarzuela estuviera entre el grupo de las que no merecieron ser recordadas por el actor al pasar "sin pena ni gloria" por la cartelera de estrenos de aquel año.

16 Tomás luceño y Carlos Fernández Shaw, Don Lucas del Cigarral, en La Novela Teatral, 235 (1921), p. 27 b. 
sufriendo con esa situación. Sin duda, allí se produce la escena más divertida de toda la zarzuela, escena en la que tiene un papel destacado nuestro gracioso:

(Don Lucas que se ha puesto en pie al empezar la cencerrada, y al cual han estado sujetando Isabel, don Antonio y algunos de los invitados, no puede contenerse al fin y se abre paso entre el público, espada en mano, dirigiéndose al tablado donde representan el entremés. Asombro y espanto de los cómicos.)

Don Lucas ¡Basta! ¡Basta! ¡Basta!

¡Voy por ti bribón!

(Don Lucas arrastra, cogido de una oreja, a Juan Rana y le trae al proscenio; los demás cómicos les siguen, y los invitados, con el resto de los personajes, rodean a don Lucas y a los cómicos; confusión, alboroto, etc. Cesa la cencerrada.)

DON Lucas ¡Te he de matar, bellaco y mal nacido!

RANA ¡Señor, que yo la culpa no he tenido!

DON Lucas ¿QQuién metiote en hacer de mí una copia y en tu cara pintar la mía propia, al punto de que dudo en este instante si eres don Lucas tú y yo el copiante?

Doña Alfonsa Déjale, hermano, no busques la culpa donde no está; busca el menguado delito en quien te fue desleal desde el comienzó.

Don LucAS (Que ha soltado ya a Juan Rana, el cual, con su gente, desaparece en cuanto se ve libre.)

:Ay, hermana, gracias a Dios quiero dar porque te he visto una vez discurrir con claridad ${ }^{17}$.

Como indica la última de las acotaciones, Juan Rana se escabulle entre bastidores para no volver a aparecer en escena

${ }^{17}$ Ibid., pp. 31 b-32 a. 
hasta que un buen día, ochenta y ocho años más tarde, el ingenio de José Sanchis Sinisterra decide sacarlo de nuevo a las tablas, aunque esta vez completamente solo, e imagina un supuesto enfrentamiento entre Cosme Pérez y el personaje que éste había creado, es decir, un enfrentamiento consigo mismo. La pieza de Sanchis Sinisterra se basa, precisamente, en lo que denomina "la agobiante interdependencia" que se estableció entre un actor que consiguió fama sin igual gracias al papel que creó e interpretó (y que le hubiera sido impensable conseguir de otra manera), y un personaje que, a su vez, se convirtió en el favorito del público gracias a las características y talento del actor que le dio vida. Se formaba así una combinación beneficiosa en apariencia, pero que el autor valenciano siente asfixiante y frustrante para un actor sentenciado a la dulce condena de interpretar durante toda su vida el mismo papel, exitoso, pero mecánico y carente de creatividad (si es que pretendía tener un lugar en el competitivo panorama teatral de la época). Según cuenta el autor en la introducción a la pieza, la propuesta sugerente que desarrolla le vino tras el conocimiento de una noticia de comienzos de la década de los años cuarenta del siglo XVII. Han transcurrido apenas diez años después de que el personaje ha encumbrado a Pérez a la cima de la fama teatral de la época, y se insinúa que el actor planea su retiro de los escenarios, se encuentra "indeciso porque no quiere representar"18. Sanchis Sinisterra ${ }^{19}$, extrañado por este hecho, se pregunta si "este deseo de abandonar el teatro ¿se debe tal vez a la necesidad de desprenderse de un personaje, de una máscara, que ya amenaza su identidad?”20.

18 La referencia a esta noticia se puede encontrar en Emilo Cotarflo, Colección de entremeses, loas, bailes, jácaras y mojigangas (desde mediados del siglo XVI a mediados del siglo XIII), Madrid, 1911, t. I, p. clix a. (Existe una ed. facs. de esta obra con est. prelim. e índices de J. L. Suárez y A. Madroñal, Universidad, Granada, 2000).

${ }^{19}$ Mísero Próspero y otras breverias. Monólogos y diálogos, La Avispa, Madrid, 2000 , p. 82.

${ }^{20}$ El escritor Marcelo Soto ha imaginado a Juan Rana también como personaje de novela en su obra Las bodas tristes (Apóstrofe, Barcelona, 1999). En ella, un Juan Rana muy novelesco, valga la redundancia, aparece como uno de sus protagonistas. El personaje es descrito físicamente como un hombre muy corpulento, moreno, barbado, y con "...facciones de hombre de mar, pero con una depuración de rasgos que le daba el mismo aire culto, y en cierto modo austero, de los retratos de Séneca" (p. 133). El personaje (que actúa de tercero proporcionando los desvanes de su casa para que Felipe IV consume sus 
La obra, titulada El canto de la rana ${ }^{21}$ (parafraseando, según explica el autor, "el título y la situación inicial de un famoso texto de Antón Chejov, El canto del cisne") ${ }^{22}$, presenta a Cosme Pérez en un escenario a oscuras, vacío de público, "más solo que la luna, harto de vino, olvidado y dormido como un fardo gotoso" 23 , justo después de concluir la que sería su última aparición escénica, el calderoniano entremés de El triunfo de Juan Rana ${ }^{24}$. A partir de esta circunstancia, el personaje da inicio a una profunda meditación sobre el conjunto global de lo que ha sido su carrera como actor, desde el momento final de su vida. La reflexión en voz alta se produce por medio de un monólogo-diálogo de carácter esquizoide en el que el personaje adopta alternativamente las voces de Cosme Pérez y Juan Rana. Según se indica en las acotaciones, el público advierte la transformación por el cambio de voz, actitud y ademanes que muestra el actor, y por la "risa peculiar" 25 que emite desde su condición de Juan Rana.

amores adúlteros con Isabel de Guzmán, condesa de Niebla) es caracterizado, principalmente, a partir de sus tendencias no tanto homosexuales, aunque sea la vertiente que más se resalta (entre sus amantes se citan al marqués de los Vélez, uno de los ayudas de cámara personales del Rey con quien mantiene relaciones en el mismo Alcázar; y un joven actor llamado José Pascual, antaño especializado en papeles femeninos y al que ahora es habitual verlo haciéndose pasar por una dama en el Palacio Real), sino bisexuales. El cómico se convierte, por una parte, en el cicerone del marqués de Arce, que lleva a cabo la investigación criminal para resolver el asesinato de su prima hermana, la anteriormente citada condesa de Niebla, en un Madrid sórdido y decadente del cual la casa de Rana parece ser el epicentro; por otra, en el guía íntimo que ayuda a don Sebastián de Arce a descubrir los secretos de la pasión y el deseo. No podemos entrar más en detalle en esta obra pues excedería los límites de este trabajo, dedicado, exclusivamente, al ámbito teatral.

${ }^{21}$ El estreno de la obra se llevó a cabo en el foro La Gruta del Centro Cultural Helénico de la ciudad de México. El papel único de Cosme PérezJuan Rana fue interpretado por el actor mexicano Oscar Yoldi, en una puesta en escena dirigida por Rodrigo Johnson. La fecha de composición de la obra, según noticia aportada por el autor, hay que situarla entre los meses de junio y agosto de 1987, aunque realizó unas "primeras tentativas" entre 1983 y 1984.

${ }^{22}$ Véase SanciIIs Sinisterra, op. cit., p. 82.

23 Ibid., p. 84.

${ }^{24}$ La pieza se estrenó en Palacio el 29 de enero de 1672, intercalada entre la primera y la segunda jornada de la comedia, también obra de Calderón, Fieras afemina Amor.

25 De algunas referencias más o menos indirectas que se pueden hallar en varias de las piezas protagonizadas por Rana (como, por ejemplo, La loa de Juan Rana, de Moreto, o Los sitios de recreación del rey, de Calderón), se puede colegir que su particular timbre de voz se utilizó con relativa frecuencia con fines cómicos. En otro de sus entremeses, Pipote en nonbre de Juan Rana, 
El Cosme Pérez que propone Sanchis Sinisterra es un personaje desesperado ante la tragedia personal que le supone haberse visto forzado a hacer no lo que hubiera deseado (ser un renombrado galán de comedia), sino lo que le impusieron las circunstancias (convertirse en el bobo-bufón por antonomasia del teatro breve). Por primera vez en el corpus juanranesco encontramos a Pérez rebelándose ante el personaje que interpretó durante la mayor parte de su carrera como actor, a causa del robo de identidad que ha sufrido por parte de Rana:

...¿¿No reconocen esta panza y esta caraza de bollo toledano? ¡Soy Juan Rana, señores, para servirles... el almuerzo! (Emite una risa peculiar... pero la interrumpe bruscamente y grita con su voz, furioso consigo mismo.) ¡Miento! No soy Juan Rana, sino Cosme Pérez... Cosme Pérez soy, representante. ¿No me conocen? (Refunfuñando.) Cierto que ahora me ven vestido de Juan Rana, pero ello es por haber representado aquí esta noche un entremés... "El triunfo de Juan Rana"...26.

El clímax argumental de la pieza llega cuando, en el colmo grotesco de la dominación que el personaje ajerce sobre el actor, éste, apremiado por la necesidad de aliviar su vejiga tras el consumo de una gran cantidad de vino, se ve imposibilitado a hacerlo debido a la enorme cantidad de ropas y postizos que le han tenido que colocar para caracterizarlo convenientemente como Juan Rana:

...ya no puedo aguantar más el vaciarme (Intenta de nuevo desatarse los calzones.) ¡Válgame Dios!... Difícil me lo ponen estas ropas... iY cómo me han fajado los malditos para simular la panza de Juan Rana!... (Bajo los calzones, que no ceden, aparecen abultados refajos.) Preso estoy bajo tanto postizo... y hasta la bragueta tiene embozada la salida... (Se va desesperando.) Calma, huroncillo mio, yo te liberaré... No te derrames ahora, por la ilusión de la huida... Aguarda, aguarda, que encontraré el camino hasta la ma-

de Luis Quiñones de Benavente, uno de los personajes hace mención a la risa falsa característica del personaje: "SALVADOR - Simple discreto, que por tu donaire / mereciste que fueses / perpetuo alcalde de los entremeses, / dando al vulgo sentencias avisadas, / a veces truecas por tus alcaldadas. / Rana, que con graciosos ademanes / quitas el gusto a más de dos faisanes / que con tu risa falsa / para hacerse comer que buscas salsa, / suplicote que quieras remediarme" (cito por CotaRelo, op. cit., t. 2, p. 714 b).

26 SANChis SinisterRa, op. cit., p. 85. 
driguera... (Los postizos parecen no acabarse nunca.) Y, cuando no, hallaré manera de desenfardelar ese atadijo de cintas... paños... guatas... cueros y entretelas, con que me han aforrado todo el... (Patalea furioso.) ; Maldito envoltorio! ¿No has de dejarme libre ni en trance tan menudo? ¿Hasta el mear me estorbarás, terco Juan Rana? ¿No te basta el haberme usurpado media vida, siéndome cárcel y tapujo y máscara? ¿Es poca cosa arrinconarme el nombre? Que ya por Cosme Pérez, vive el cielo, ni yo mismo atino a conocerme... ¿La edad me negarás también, rana trufosa, y el honesto decoro que las canas conceden a las necesidades corporales? ¿Quieres volverme a hacer niño de teta, biznieto de mí mismo, desaguándome todo en mis pañales? (Desiste, rabioso, de quitarse el disfraz y llama a gritos.) iJerónimo! ;Manuela! ;Escamilla! ¡A mí! ¡Acudid presto, que me meo! ¡Favor, soco...! (Se interrumpe de golpe, queda inmóvil y, poco a poco, va calmándose. Le invade una sonrisa placentera. Es evidente que se ha librado de su problema...) No es menester que acudas, Escamilla... (pp. 86-87).

Esta cruel escena en la que a partir de una propuesta presumiblemente cómica se pone de manifiesto la tragedia personal del personaje, sirve como punto de partida al despiadado duelo que se entabla entre el actor y su "máscara" mediante una serie de recriminaciones mutuas que se van sucediendo. Será Pérez quien, tras rememorar de un modo idealizado sus supuestos exitosos inicios en el mundo del teatro, comience arremetiendo contra Rana al acusarlo de haber sido la causa de que su prometedora carrera como actor serio diera al traste:

...jPeste para Juan Rana! Peste y muerte, sí, por más que te echaran tantos vítores en el entremés... (Remeda, furioso, los versos.)

"Viva Juan Rana! ;Viva sin desvelo! ¿Viva hasta que la rana tenga pelo!"

Pues yo digo: malditos sean el día y la hora en que te metiste en mi vida. ¡Malditos una y mil veces!... ¿Qué? ¿Te escuece, ranilla? ¿No sospechabas que guardara contra ti tanto resquemor? ¿Creías que te estaba agradecido por haberme traído fama, fortuna y favores durante tantos años?... Poco sabes de mí, si tal pensabas... Poco y repoco te has parado a considerar quién o qué cosa fuera este armazón de huesos y pellejos que tantos años ha aguantado el peso de tu panza y bobería, que ha llevado tu sayo y vara de alcalducho sin seso ni substancia, que ha espetado en mil tablados tus versos flatulentos, tus desabridos donaires, tus patrañas... (p. 88). 
La respuesta de Rana no se hace esperar, decide atacar a Cosme donde más le duele, en lo más hondo de su amor propio: le recuerda que aquellos comienzos que él rememora de un modo tan romántico no fueron más que los primeros pasos de un actor abocado a ocupar siempre un papel muy secundario en las compañías. De no haber sido por la fama y relevancia que le proporcionó un buen día el papel de Juan Rana, Cosme Pérez sería un don nadie, por lo que, en realidad, éste no debería sentir tanto resentimiento hacia la máscara que creó, sino más bien considerarla una buena amiga a la que habría que estar muy agradecido:

...¡Miren al simple bobazo de Juan Rana, cómo se empina y encarama hasta nombrarse amigo de Cosme Pérez! ¿'Tan poca cosa he de ser yo, para amigarme con un remedo como tú, con un garabato de persona? (Retoma los modos de Juan Rana.) Garabato seré, pero de más firme trazo que no tú, Cosmecillo, que si ahora te precias de ser alguien, cosa bien poca y apocada fuiste hasta topar conmigo. $Y$ si a mí mismo me encaramo, como dices, muy más te empiné a ti, y aún a todos los tuyos. Mira, si no, dónde te encuentras hoy, y acuerda cuáles fueron tus principios. (Rie extrañamente, pero su risa se trunca de golpe y vuelve a ser Cosme.) ¡Mejor que tú sé cuáles fueron mis principios!... sino que no vienen al caso... A los medios, a los medios me remito, a mi mediana edad, a la flor de mi vida y frutos de mi oficio... (Nuevamente como Juan Rana.) Pepinos, calabazas, nabos, tomates... (Cambia bruscamente a Cosme.) ¿Qué murmuras, bellaco? (Prosigue como Juan Rana.) Razonaba de frutos, señor Pérez... ¿No eran estos que digo los más que cosechabas con tu oficio, en la flor de tu vida? (Rie sardónicamente.) ¿Qué oficio ni qué flor llamas a aquel andar arrastrando las nalgas de compañía en compañía, de comedia en comedia, de papel en papel? (pp. 88-89).

En un desesperado intento de rebeldía final contra su implacable sino, Pérez rebusca entre los vestidos y accesorios que han quedado olvidados sobre el escenario una vez finalizada la comedia para la que han sido utilizados (se trataba, como ya quedó indicado en nota de la también calderoniana Fieras afemina Amor) para vestirse con ellos y demostrarse a sí mismo la convicción que desde siempre le ha rondado la cabeza: su capacidad para haber sido un destacado actor principal dentro del considerado teatro elevado ${ }^{27}$.

${ }^{27}$ Se dirá a sí mismo: “¡Pero yo hubiera podido ser galán osado, amigo leal... soldado... venerable... enemigo discreto... padre fiero... consejero... valeroso... noble... grave... caballero...!" (p. 90). 
Sanchis Sinisterra exhibe tan desoladora escena de la siguiente manera:

(Busca entre los bultos que yacen por el suelo y encuentra una peluca, un gran sombrero, un amplio y lujoso jubón, una brillante espada... Mientras habla, se los irá poniendo sobre el grotesco disfraz de Juan Rana, con lo que su apariencia final será, más que ridícula, monstruosa.) Voy... sí... voy a cubrir su burda facha con nobles atavíos... voy a borrar de mí su torpe bulto... Seré, por esta noche, no una rana ridícula, sino el actor que fui, sí, Cosme Pérez... capaz de hacer suspirar y enternecerse a nobles auditorios... ¿Me escuchas, lerdo? (Zarandea los rellenos que cuelgan de su vientre y trata de introducirlos de nuevo en sus calzones, cubriéndose luego con el fantasioso jubón.) Pues que no puedo arrancar tus malditos postizos, aquí se enterrarán, bajo estas galas ...Y en ellas revestido, verás quién pude ser en los tablados ...Y si la reina, otrora, me dio una pensión de por vida por lo mucho que la hice reír, agora me la diera doblada por hacerla llorar... (Ha quedado ya ataviado como un grotesco y deforme remedo de personaje mitológico, al estilo de las obras cortesanas de Calderón. Queda un momento inmóvil, jadeando porel esfuerzo, mientras busca en su memoria algún pasaje adecuado...) (p.91).

Como podemos comprobar, la triste paradoja reside en el hecho de que realmente consigue lo que pretende, hacer llorar, incluso antes de proponérselo. Los intentos de Cosme por traer a la memoria alguno de aquellos versos elevados que recitó en las comedias en las que participó siendo joven son inútiles, por lo que, poco a poco, asistimos a un proceso de claudicación y resignación en el que, según se va despojando de las galas y accesorios que se había colocado con anterioridad, manifiesta su incapacidad para hacer frente e imponerse a su suerte. Debe aceptar el triunfo que sobre su persona ha tenido y siempre tendrá su personaje, al que el público y la historia recordarán siempre, seguramente mucho después de haber olvidado a quien un día lo hizo vivir sobre las tablas:

(Vuelve a reíry va despojándose del sombrero, de la peluca, del jubón...) No, no soy de los primeros que se olvidan de quién son... Ni seré de los últimos... ¿Lo has olvidado tú, Cosme, en cubriéndote con estas.... galas? ¿Con ellas quieres borrarme... y borrarte? Y borrarte digo, sí, viejo esmirriado... Porque, ¿qué quedará de ti si a mí me entierras y destierras? ¿Qué pálido estafermo serás sin tu Juan Rana? (Ha quedado ya despojado del disfraz cortesano.) Croac... croac... croac... croac... La rana canta en su charco... Y toda la corte y grandeza de España ríe... y le llena por ello la panza... ¿Qué más se puede de- 
sear, en estos tiempos? (Súbitamente, el teloncillo del Coliseo del Buen Retiro comienza a desplegarse, al tiempo que se escucha una creciente salva de aplausos. Cosme queda un momento atónito, pero al punto "Juan Rana" reacciona por él y ejecuta una servil y bufonesca reverencia.) (pp. 93-94).

El espectro de situaciones en las que se ha visto involucrado Juan Rana a lo largo de sus más de tres siglos y medio de vida no ha podido ser más variado y completo. No resulta nada extraño, por lo tanto, que a un personaje con una trayectoria como la suya lo encontremos en los albores del siglo XXI sufriendo una de las frecuentes crisis existenciales que aquejan al hombre moderno, provocada, en su caso, por la conciencia del precio personal que se ha visto obligado a pagar para poder saborear la dulzura de las mieles de la fama. Cosme Pérez podría perfectamente hacer suyas aquellas palabras que Francisco Santos en su obra El diablo anda suelto (Madrid, 1677) pone en boca del bufón que, como nuestro personaje, lleva a cabo una especie de examen vital en el que deja patente algo que muy a menudo y con excesiva facilidad parece olvidarse a la hora de hacer referencia a este tipo de personajes, algo que ni por asomo se concebía en la época, su dignidad humana:

...quité pesares, di alegrías, entretuve el tiempo, fui querido y buscado, lucí y medré y llegué a puertos donde granjeé alhajas y hacienda, hice a muchísimos bobos, sin serlo yo, pero no puedo negar la verdad aquí, donde la dice la boca del condenado: fui bufón ${ }^{28}$.

¿Podrá Cosme Pérez-Juan Rana sobreponerse a esta nueva y desconocida circunstancia? ¿Será capaz de vencer el drama personal que se le propone (estamos ante el que es, hasta el momento, el único papel trágico de su larguísima carrera) y aceptar su condición profesional sin que esto afecte negativamente su dignidad personal? ¿Tendrá este personaje, que ha sabido superar todas las adversidades externas imaginables, la capacidad para recuperarse de su frustración interior? Sólo el tiempo y la fascinación que su figura seguirá despertando podrán darnos la respuesta.

Francisco Sáez Raposo Vanderbilt University

${ }^{28}$ Fernando Bouza, Locos, enanos y hombres de placer en la Corte de los Austrias, Temas de Hoy, Madrid, 1996, p. 66. 